\title{
Molecular Characterization of Two Types of Resistance in Sunflower to Plasmopara halstedii, the Causal Agent of Downy Mildew
}

\author{
Osman Radwan, Mohamed Fouad Bouzidi, and Said Mouzeyar
}

First author: National Soybean Research Center, 1101 W. Peabody Drive, University of Illinois at Urbana-Champaign, Urbana 61801; and second and third authors: UMR 1095 INRA-UBP, GDEC Génétique Diversité Ecophysiologie des Céréales, Université Blaise Pascal, 24 avenue des Landais 63177 Aubière Cedex, France.

Accepted for publication 11 February 2011.

\begin{abstract}
Radwan, O., Bouzidi, M. F., and Mouzeyar, S. 2011. Molecular characterization of two types of resistance in sunflower to Plasmopara halstedii, the causal agent of downy mildew. Phytopathology 101:970-979.

Depending on host-pathotype combination, two types of sunflowerPlasmopara halstedii incompatibility reactions have previously been identified. Type I resistance can restrict the growth of the pathogen in the basal region of the hypocotyls, whereas type II cannot, thus allowing the pathogen to reach the cotyledons. In type II resistance, a large portion of the hypocotyls is invaded by the pathogen and, subsequently, a hypersensitive reaction (HR) is activated over a long portion of the hypocotyls. Thus, the HR in type II resistance coincides with a higher induction of $h s r 203 j$ sunflower homologue in comparison with type I resistance, where the HR is activated only in the basal part of hypocotyls. Although the pathogen was not detected in cotyledons of type I resistant plants, semiquantitative polymerase chain reaction confirmed the early
\end{abstract}

ABSTRACT

Plant-pathogen interactions, particularly those involving biotrophic parasites, are governed by specific interactions between pathogen avirulence ( $a v r$ ) gene loci and alleles of a corresponding plant disease resistance $(R)$ locus. When corresponding $R$ and $a v r$ genes are present in both host and pathogen, the result is disease resistance. If either is inactive or absent, disease results $(9,18)$. During incompatible plant-pathogen interactions, recognition of a potential pathogen often results in a hypersensitive response (HR), with the activation of programmed cell death (PCD) at the site of the attack designed to halt the spread of the pathogen. During an HR, a small set of cells close to the infection site undergoes rapid PCD, usually within 12 to $24 \mathrm{~h}$ of inoculation (20). This HR is characterized by numerous physiological and molecular changes, such as depolarization of the plasma membrane, changes in respiration rates, the production of nitric oxide (NO) and reactive oxygen species (ROS), an oxidative cross linking of various cell wall compounds, and the production of pathogenesis-related $(\mathrm{PR})$ proteins $(7,16)$. ROS such as hydrogen peroxide $\left(\mathrm{H}_{2} \mathrm{O}_{2}\right)$, superoxide $\left(\mathrm{O}_{2}^{-}\right)$, hydroxyl radical $\left(\mathrm{OH}^{-}\right)$, and singlet oxygen control many different processes in plants, such as growth, the cell cycle, PCD, hormone signaling, biotic and abiotic stress responses, and development $(19,21,30)$.

Corresponding author: O. Radwan; E-mail address: oradwan@illinois.edu

* The $\boldsymbol{e}$-Xtra logo stands for "electronic extra" and indicates that the online version contains two supplemental tables and one supplemental figure. Figures 1 and 2 appear in color online.

doi:10.1094/PHYTO-06-10-0163

(c) 2011 The American Phytopathological Society abundant growth of the pathogen in cotyledons of susceptible plants by 6 days postinfection (dpi). This was in contrast to scarce growth of the pathogen in cotyledons of type II-resistant plants at a later time point (12 dpi). This suggests that pathogen growth differs according to the host-pathogen combination. To get more information about sunflower downy mildew resistance genes, the full-length cDNAs of RGC151 and RGC203, which segregated with the $P l_{A R G}$ gene (resistance type I) and $\mathrm{Pl}_{14}$ gene (resistance type II), were cloned and sequenced. Sequence analyses revealed that RGC151 belongs to the Toll/interleukin-1 receptor (TIR) nucleotide-binding site leucine-rich repeat (NBS-LRR) class whereas RGC203 belongs to class coiled-coil (CC)-NBS-LRR. This study suggests that type II resistance may be controlled by CC-NBS-LRR gene transcripts which are enhanced upon infection by $P$. halstedii, rather than by the TIR-NBS-LRR genes that might control type I resistance.

Additional keywords: incompatible plant-pathogen interactions.

Sunflower, an important oilseed crop, is attacked by the oomycete Plasmopara halstedii, which causes downy mildew and yield losses of $\leq 85 \%$ (11). P. halstedii is an obligate parasite and there are significant numbers of physiological strains that can be distinguished by their differential virulence on sunflower genotypes $(14,40,46)$. Control of this disease in sunflower is achieved mainly by genetic resistance that is conditioned by major genes denoted $P l$ (for Plasmopara). In the field, these $P l$ genes are sufficient to provide complete, dominant, and race-specific resistance.

Microscopic observations showed that both susceptible and resistant sunflower lines can be invaded by $P$. halstedii (27). However, $\approx 5$ days after root infection, an HR develops within the hypocotyls of both types I and II of resistant plants, and the fate of the infection depends on both the $R$ gene in the host and the $a v r$ gene in P. halstedii. Mouzeyar et al. (28) described two types of resistance. In plants with type I resistance, the pathogen is restricted to the basal area of the hypocotyls whereas, in plants with type II resistance, the hypocotyls could be completely invaded and the cotyledons are reached by the pathogen although, in most cases, the pathogen does not reach the true leaves $(27,28)$. This so-called cotyledon limited infection (CLI), characteristic of type II resistance, was first described by Gulya et al. (14) and Sackston (43) and is a general phenomenon found in sunflower$P$. halstedii interactions.

Four genes involved in resistance to $P$. halstedii have been reported: (i) the $P l_{1} / P l_{6}$ genes on linkage group (LG) $8(6,10)$, (ii) the $P l_{5} / P l_{8}$ genes on LG13 $(35,36)$, (iii) the $P l_{A r g}$ gene on LG1 (8), and (iv) two newly mapped genes $\left(P_{13}\right.$ and $\left.P l_{14}\right)$ on LG1 independent of the $P l_{A r g}$ gene $(4,8,29)$. In recent work, Radwan et al. (37) identified more $R$ gene candidates (RGCs) related to the two clusters of downy mildew resistance on LG8 that belong to 
the Toll/interleukin-1 receptor (TIR) nucleotide-binding site leucine-rich repeat (NBS-LRR) class and on LG13 that belong to the coiled-coil (CC)-NBS-LRR class.

Interestingly, resistance to the same race of $P$. halstedii seems to be governed by genes belonging to different classes of plant $R$ genes; however, the molecular and cellular bases of these resistances have never been extensively compared. Therefore, sunflower lines harboring different clusters that confer resistance to the same race of $P$. halstedii have been used to compare and to find out the distinctions between them using cellular and molecular approaches.

\section{MATERIALS AND METHODS}

Plant materials and infection procedures. For the compatible interaction, the susceptible line HA89 was used. HA89 (PI 599773) is a public oilseed sunflower inbred maintainer line that was released by the United States Department of AgricultureAgricultural Research Service (USDA-ARS) in 1971. For the incompatible interaction, two sunflower inbred lines with type I resistance were used. Line HA335 carries the $P l_{6}$ gene and line RHA419 carries the $P l_{A r g}$ gene. Two sunflower inbred lines with type II resistance were used. RHA340 carries the $P l_{8}$ gene and 29004 carries $\mathrm{Pl}_{14}$ gene. Seed of the HA89, RHA340, RHA419, and HA335 lines were obtained from the USDA-ARS National Plant Germplasm System (http://www.ars-grin.gov/npgs), while seed of 29004 were obtained from Advanta Semillas Company (Balcarce, Argentina).

The inoculum of $P$. halstedii pathotype (P) 300 was originally obtained, as a kind gift, from Dr. T. Gulya (USDA-ARS, Fargo, ND). P 300 was used in this study for two reasons: (i) this pathotype is widely spread in North America and Europe and (ii) it was used in an earlier study to characterize type II resistance $(38,39)$. Infection procedures and the conditions prevailing in the growth chambers were as described by Mouzeyar et al. (27) and Radwan et al. (39). Briefly, sunflower seed were surface sterilized with $10 \%$ hypochlorite solution following by washing several times in water and then were allowed to germinate for $48 \mathrm{~h}$ at $24^{\circ} \mathrm{C}$. Roots of 2 -day-old seedlings were then infected by immersing the entire seedling in $10 \mathrm{ml}$ of a suspension containing $5 \times 10^{4}$ zoosporangia $\mathrm{ml}^{-1}$. Five hours later, the zoosporangia suspension was removed and the seedlings were transferred to the growth chamber in a tray containing sterile soil-less growing medium (Sunshine Mix, LC1; Sun Gro Horticulture Inc., Bellevue,
WA). The growth conditions were $18 \pm 1^{\circ} \mathrm{C}$; a light-and-dark cycle of 16 and $8 \mathrm{~h}$, respectively; and light intensity of $\approx 200 \mu \mathrm{E}$ $\mathrm{m}^{-2} \mathrm{~s}^{-1}$. Control plants underwent the same procedures, except that sterile water replaced the zoosporangia suspension. Samples from hypocotyls and cotyledons of infected and mock-infected plants were collected separately at 1.5, 3, 6, 9, 12, and 15 days postinfection (dpi). Each collected sample consisted of eight cotyledons or hypocotyls from different plants. The experiments were repeated three times on different dates using new preparations of $P$. halstedii inoculum to obtain three independent biological replications. In addition, three technical replications of each biological replicate were carried out. Error bars representing standard errors estimated from three biological replicates were calculated from standard deviations.

RNA manipulations and reverse-transcriptase polymerase chain reaction procedures. Total RNA was separately extracted from the entire hypocotyls and the cotyledons of the five lines that were used in this study using a TRIzol kit (Invitrogen, Carlsbad, CA) and Phase Lock Gel (Brinkmann Instruments, Inc., Westbury, NY) according to the manufacturer's protocol, followed by a chloroform extraction. Further cleanup was performed using the RNeasy mini kit (Qiagen, Valencia, CA). All of the RNA samples were checked with a Bioanalyzer 2100 (Agilent Technologies, Palo Alto, CA) to verify that RNA had not degraded. The concentration of total RNA was determined with a NanoDrop ND-1000 Spectrophotometer (NanoDrop Technologies, Wilmington, DE). Total RNA was treated with DNase I (Invitrogen) to remove genomic DNA contamination. DNase-treated RNA $(2 \mu \mathrm{g})$ was reverse transcribed using the SuperScript III First-Strand Synthesis System for reverse-transcriptase polymerase chain reaction (RT-PCR) (Invitrogen). A “minus" RT-PCR reaction was used to test each RNA sample for genomic DNA contamination. For this, no RT enzyme was added during the cDNA synthesis reaction.

Measurement of gene expression for defense and signaling components. The transcriptional expression of each gene was analyzed using real-time PCR, except for P. halstedii Ph-tefl, for which duplex semiquantitative PCR was used. For real-time PCR, cDNA was diluted to a final concentration of $30 \mathrm{ng} / \mu \mathrm{l}$ and $2 \mu \mathrm{l}$ was used in a $20-\mu \mathrm{l}$ PCR mix containing $8.9 \mu \mathrm{l}$ of Brilliant QPCR Master Mix (catalog number 600549; Stratagene, Cedar Creek, TX) and $0.2 \mu \mathrm{M}$ each primer. A standard PCR program was carried out under the following conditions: an initial denaturation step at $95^{\circ} \mathrm{C}$ for $10 \mathrm{~min}$, followed by 40 cycles of $15 \mathrm{~s}$ at $95^{\circ} \mathrm{C}$,

TABLE 1. Sunflower and Plasmopara halstedii gene-specific primers used in semiquantitative and quantitative polymerase chain reaction

\begin{tabular}{|c|c|c|c|c|c|}
\hline$\overline{\text { Gene }^{\mathrm{a}}}$ & Primer sequence $^{\mathrm{b}}$ & $\mathrm{TM}\left({ }^{\circ} \mathrm{C}\right)^{\mathrm{c}}$ & Size $(b p)^{d}$ & Accession $^{\mathrm{e}}$ & Reference \\
\hline \multirow[t]{2}{*}{$H s r 203 j$} & F. 5'-CTAAGGGAGACTTCAACCGTGTCT-3' & & & & \\
\hline & R. 5'-GTCAAGAGTTAGCATGGGAGATTG-3' & 60 & 206 & EL422223 & This study \\
\hline PR5 & F. 5'-GGATGCAACAATCCTTGCACGG-3' & & & & \\
\hline \multirow[t]{2}{*}{ Ph-tef1 } & F. 5'-GAGTTATTAAACCCGGTATGGTTG-3' & & & & \\
\hline & R. 5'-TCCATCTTCTCCGTAATCTCTTTG-3' & 60 & 331 & CB174619 & 39 \\
\hline \multirow[t]{2}{*}{ Actin } & F. 5'-GCAAAAAGCAGCTCGTCTGT-3' & & & & \\
\hline & R. 5'-AGCAGCTTCCATTCCAATCA-3' & 58 & 129 & AF282624 & 44 \\
\hline \multirow[t]{2}{*}{ PU3 } & F. 5'-CCGTGGATTCGTTTTGATGAGT-3' & & & & \\
\hline & R. 5'ATTTGGTGTCGTGATTAGGTTTGATG-3' & 58 & 183 & AF316405 & 6 \\
\hline \multirow[t]{2}{*}{ RGC203 } & F. 5'-ATTCCCAATGTTTATATCCCTCCT-3' & & & & \\
\hline & R. 5'GCATCATTCGTTGTCATCTTTATCT-3' & 58 & 223 & GU085220 & This study \\
\hline \multirow[t]{2}{*}{ RGC151 } & F. 5'-TACCAGCCTATGATGTATCTTGTTC-3' & & & & \\
\hline & R. 5'CAGGGCTAATACCATACTCCCTTAC-3' & 60 & 235 & GU085221 & This study \\
\hline
\end{tabular}


$20 \mathrm{~s}$ at the predicted melting temperature (Table 1), and $30 \mathrm{~s}$ at $72^{\circ} \mathrm{C}$. After each run, a dissociation curve was acquired to check for amplification specificity by heating the samples from 60 to $95^{\circ} \mathrm{C}$. In addition, $\mathrm{PCR}$ products were sequenced to verify that the correct amplicon was being produced. The real-time PCR data were analyzed using the $\Delta \Delta$ cycle threshold method mathematical model (24), which establishes the change in magnitude of target gene transcription in plants subjected to different treatments (i.e., infected) relative to transcription levels in control plants (mockinfected) after normalization using transcription levels of the Actin housekeeping gene (44). Because sunflower has an ef- $1 \alpha$ elongation factor, specific primers from the $P$. halstedii expressed sequence tag (accession number CB174619) were designed to amplify a cDNA fragment from a $P$. halstedii that lacks homology with the sunflower ef- $1 \alpha$ elongation factor (AAM19764). Semiquantitative PCR was carried out under the same conditions as real-time PCR but no dissociation curve was acquired. The amplification products of PCR after 40 cycles were separated on Trisborate-EDTA-agarose gels (2\%), which were subsequently stained with ethidium bromide $\left(0.5 \mathrm{mg} \mathrm{ml}^{-1}\right)$. The primers were designed using Primer 3.0 software (42), and the target product size of each primer pair is indicated in Table 1 . To amplify specific fragments from sunflower RGCs (HA-NTR11, PU3, RGC203, and RGC151), primers (Table 1) were designed from the $3^{\prime}$ untranslated region of each RGC. Three biological and three technical replicates were conducted on every comparison between control and infected tissues.

Microscopic observations. Sections from sunflower hypocotyls and cotyledons were fixed in formalin-acetic acid-ethanol (5:5:90 by volume). Free-hand sections of infected and noninfected tissues were mounted on glass slides as described by Mouzeyar et al. (28) and recorded using light microscopy provided by Axio cam HRC (Zeiss Digital Camera, New York). Aniline blue staining (47) was used to detect the pathogen.

Rapid amplification of cDNA ends PCR procedure. SMART rapid amplification of cDNA ends (RACE) cDNA amplification (Clontech, Palo Alto, CA) was used to amplify the 5' and $3^{\prime}$ ends of RGC203 and RGC151. Gene-specific and nested gene-specific primers (Supplemental Table 1) were designed based on the partial sequences (754 and 1,139 bp) of RGC203 and RGC151 (accession numbers DY904497 and EL455330, respectively). The $5^{\prime}$ and $3^{\prime}$ cDNAs were produced using $2 \mu \mathrm{g}$ of total RNA isolated from line 29004 (RGC203) and line RHA419 (RGC151). Diluted cDNA $(2 \mu \mathrm{l} ; 1 / 10)$ was used as a template for the first PCR round; then, the PCR products were diluted 3/10, and $10 \mu \mathrm{l}$ was used as a template for the nested PCR. PCR reactions $(50 \mu \mathrm{l})$ contained $1 \mu \mathrm{l}$ of Taq DNA polymerase (Advantage 2; Clontech), $1 \times$ Taq polymerase buffer, $0.2 \mathrm{mM}$ dNTPs, and $0.2 \mu \mathrm{M}$ each primer. Amplification was carried out under the following conditions: for the first PCR, an initial denaturation at $95^{\circ} \mathrm{C}$ for $5 \mathrm{~min}$ was followed by 35 cycles of $95^{\circ} \mathrm{C}$ for $10 \mathrm{~s}, 65^{\circ} \mathrm{C}$ for $30 \mathrm{~s}$, and $72^{\circ} \mathrm{C}$ for $3 \mathrm{~min}$; and, for the nested PCR, an initial denaturation at $95^{\circ} \mathrm{C}$ for $5 \mathrm{~min}$ was followed by 40 cycles of $95^{\circ} \mathrm{C}$ for $10 \mathrm{~s}$ and $68^{\circ} \mathrm{C}$ for $4 \mathrm{~min}$. The amplified products were cloned into a pCR4-TOPO vector (Invitrogen) and sequenced. Four clones each from the $5^{\prime}$ and $3^{\prime}$ ends of the RACE-PCR were chosen randomly and sequenced on both strands. To amplify the full length of these two RGCs, specific primers were designed based on the sequences of the $5^{\prime}$ and $3^{\prime}$ ends of RGC203 and RGC151. The forward primer contained the initiation codon (ATG) and the reverse primer was complementary to bases located prior to the poly $(\mathrm{A})^{+}$tail. The same cDNA template, dilution, and PCR conditions were applied as above except for the annealing temperature, where 60 and $66^{\circ} \mathrm{C}$ were used for first and nested PCR, respectively. In addition, an extension temperature of $72^{\circ} \mathrm{C}$ for 6 min was added to both first and nested PCRs. The amplified products were cloned into a pCR4-TOPO vector (Invitrogen), and two clones were completely sequenced.
DNA sequence analysis. The nucleotide and amino acid sequences were compared with sequences in the GenBank database using the BLAST analysis program (2). The sequences were aligned using the CLUSTAL X software with default options (45), and the resulting alignments were shaded using GENEDOC software (31). A neighbor-joining tree was produced from analyses of NBS amino acid similarity of RGC203 and RGC151 with those of other R protein matrices using bootstrap resampling $(k=1,000$ permutations). A phylogenetic tree was made using MEGA 3.1 (http://www.megasoftware.net/).

\section{RESULTS}

Susceptible and resistant hosts could be invaded by the pathogen. Five sunflower lines that differentially react to $P$. halstedii were used in this study. HA89 is a susceptible line. HA335 and RHA419 have type I resistance to P 300 . RHA340 and 29004 have type II resistance to P 300. Macroscopic observation from susceptible plants (HA89) showed normal downy mildew symptoms such as stunting, leaf chlorosis, and fungal sporulation in cotyledons and leaves (Fig. 1A, column 1). In both types of resistance, the infected plants show neither stunting nor chlorosis, and they appear virtually healthy. In type II resistance, the plants showed necrosis initiation with slight parasite sporulation on some cotyledons (Fig. 1A, column 3) whereas, in type I resistance, neither sporulation nor necrosis were observed (Fig. 1A, column 2). The susceptible plants (HA89) and both types of resistant plants were all invaded by $P$. halstedii but, $\approx 5$ to 6 days after root infection, an HR developed within the basal region of the hypocotyls in both types of resistance. Although the HR can extend halfway along the hypocotyls in type II resistance, the susceptible response is characterized by the absence of such a reaction (Fig. 2A, column 1). Microscopic sections from the basal region of hypocotyls from both the susceptible and the two types of resistant plants were examined at 9 dpi with $P$. halstedii. In the compatible reaction, intercellular hyphal growth with abundant haustoria and an absence of necrotic parenchyma cells was apparent in the hypocotyls (Fig. 2A, column 1) whereas, in the incompatible combination of both types of resistance, the parenchyma cells penetrated by haustoria had undergone cell death (Fig. 2A and B, columns 2 and 3). To follow the progress of the pathogen toward the cotyledons, microscopic sections from middle and upper parts of hypocotyls from susceptible and resistant lines (RHA419 and 29004 are not shown) were examined following infection by the pathogen at 12 and $15 \mathrm{dpi}$, respectively. Microscopic observations of the hostpathogen interactions indicated the presence and absence of the pathogen for susceptibility and type I resistance, respectively, while type II resistance is characterized by a collapse of some cells, indicative of an HR (Fig. 2C and D, column 3). Semiquantitative PCR detected $P$. halstedii in hypocotyls of susceptible and type I and II resistant plants (Fig. 2E, columns 1, 2, and 3). The pathogen was detected in the hypocotyls of susceptible and type II-resistant plants 1.5 to 15 dpi whereas, in type I resistance, it was detected 1.5 to 9 dpi. Semiquantitative PCR (Fig. 2E) reflected the abundant growth of the pathogen in the susceptible line and substantially less growth of the pathogen in the type IIresistant lines.

$P$. halstedii can reach the cotyledon of type II-resistant plants. The morphological observations of cotyledons (Fig. 1A), microscopic examination (Fig. 1B and $\mathrm{C}$ ), and semiquantitative PCR (Fig. 1D) provide evidence that the pathogen reaches the cotyledons of susceptible and type II-resistant plants. Hyphal growth with abundant haustoria and an absence of necrotic parenchyma cells was apparent in the cotyledons of susceptible plants at 12 and 15 dpi (Fig. 1B and C, column 1). Microscopic examination of sections from cotyledons of type I- and II-resistant plants, at 12 and $15 \mathrm{dpi}$, confirmed an HR in the case of type II 
resistance, whereas the cells appeared normal in the case of type I resistance (Fig. 1B and C, column 2). In type II resistance, cotyledon cells close to the hyphae showed a collapse indicating an HR (Fig. 1B and C, column 3). Primers specific for the Ph-tefl elongation factor of $P$. halstedii (Fig. 1D) confirmed the presence of the pathogen in the cotyledons of susceptible and type II-resistant plants. The pathogen reached the cotyledons of susceptible plants early (6 dpi), and then its growth increased gradually until $15 \mathrm{dpi}$. On the other hand, the pathogen did not reach the cotyledons of type II-resistant plants until $12 \mathrm{dpi}$ and then its growth decreased by $15 \mathrm{dpi}$. Thus, once again, these results suggest that pathogen growth differs according to the host-pathogen combination.

Molecular characterization of RGC203 and RGC151. Two gene-specific primer pairs were designed from the partial sequence of RGC203 (accession number DY904497) and RGC151 (accession number EL455330) to facilitate isolation of the full- length cDNA sequences. Four clones of each of the $5^{\prime}$ and $3^{\prime}$ ends were randomly chosen and sequenced. The partial sequences of the four 3 '-end clones indicated that there are putative stop codons before the poly $(\mathrm{A})^{+}$tail. To amplify the full-length cDNA of RGC203 and RGC151, the sequences of the $5^{\prime}$ and $3^{\prime}$ ends of the RACE-PCR products were used to design specific primers. A single band produced by long-distance PCR for each RGC was cloned and sequenced. The full sequences of two clones from each RGC revealed that RGC203 and RGC151 cDNAs contain 3,233 bp (accession number GU085220) or 3,409 bp (accession number GU085221), with one open reading frame encoding 949 and 1,021 amino acids, respectively. The amino acid sequence predicted from RGC203 was divided into three domains (Supplemental Figure 1). The first is a $\mathrm{CC}$ domain (amino acids 1 to 179). The second domain is an NBS (amino acids 180 to 467) region. The third domain is an LRR, and includes the $\mathrm{C}$ terminus (amino acids 468 to 949). Several LRR motifs were detected in
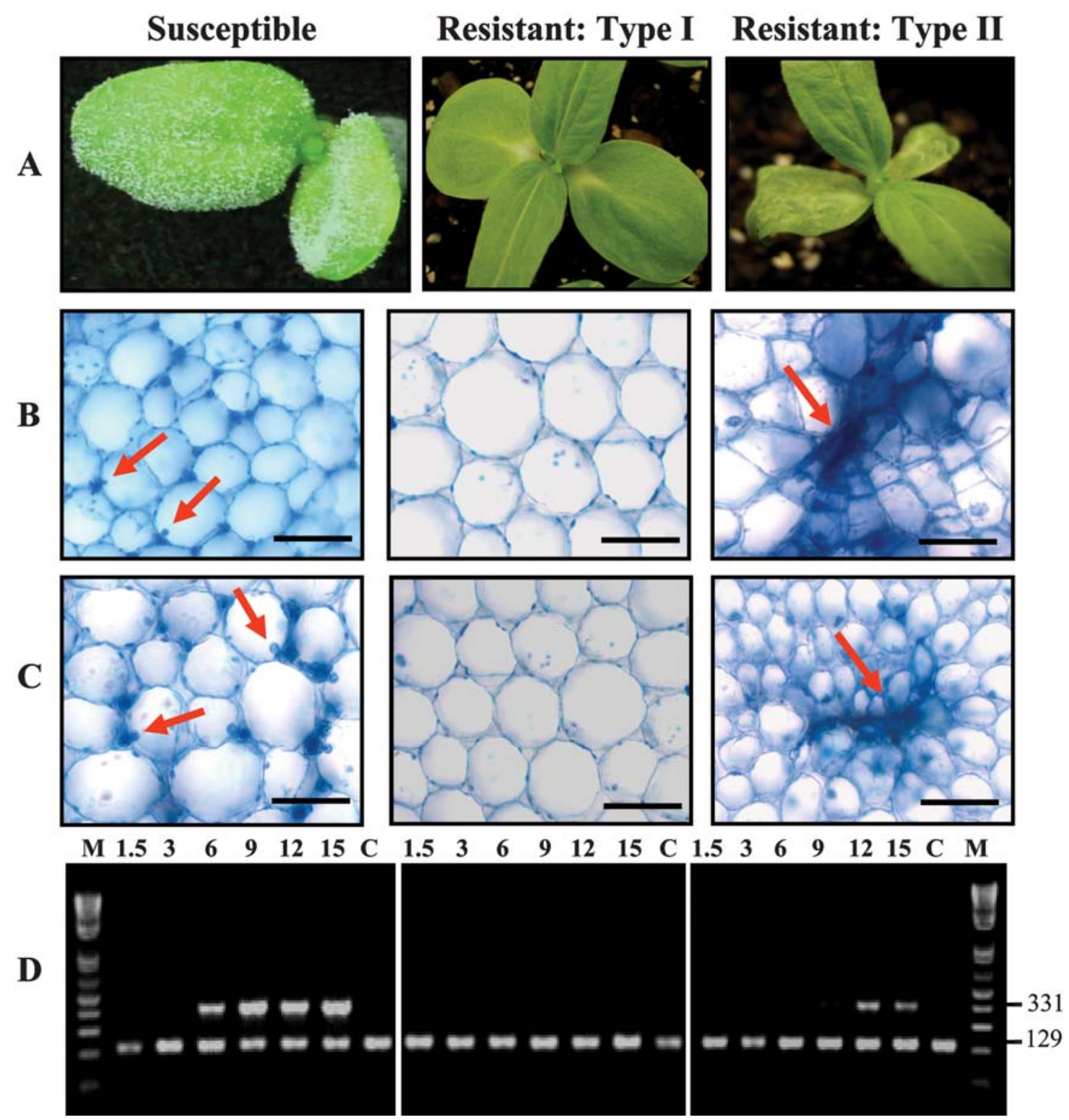

Fig. 1. Morphological, cellular, and molecular differences between cotyledons of sunflower lines HA89 (susceptible), HA335 (type I), and RHA340 (type II) after 15 days of root infection by Plasmopara halstedii. A, Pathogen sporulation and hypersensitive reaction (HR) can be noted on cotyledons in case of susceptible (HA89) and resistant type II (RHA340) interactions, which is confirmed by the microscopic examination of cotyledon sections at B, 12 and $\mathbf{C}, 15$ days postinfection. Arrows indicate haustoria of $P$. halstedii in the compatible reaction and the HR in incompatible combination. Black bars $=20 \mu \mathrm{m}$. D, Semiquantitative polymerase chain reaction (PCR) detected the Ph-tefl gene of $P$. halstedii (higher band, 331 bp) in cotyledons of susceptible and type I- and II-resistant plants. Actin (lower band, $129 \mathrm{bp}$ ) was used as an internal reference to quantify sunflower cDNA. M = DNA ladder (Invitrogen, Carlsbad, CA), $\mathrm{C}=$ control, and numbers $=1.5$ to 15 dpi.. Microscopic observation and semiquantitative PCR are derived from one representative experiment of three independent biological replications. 
Susceptible
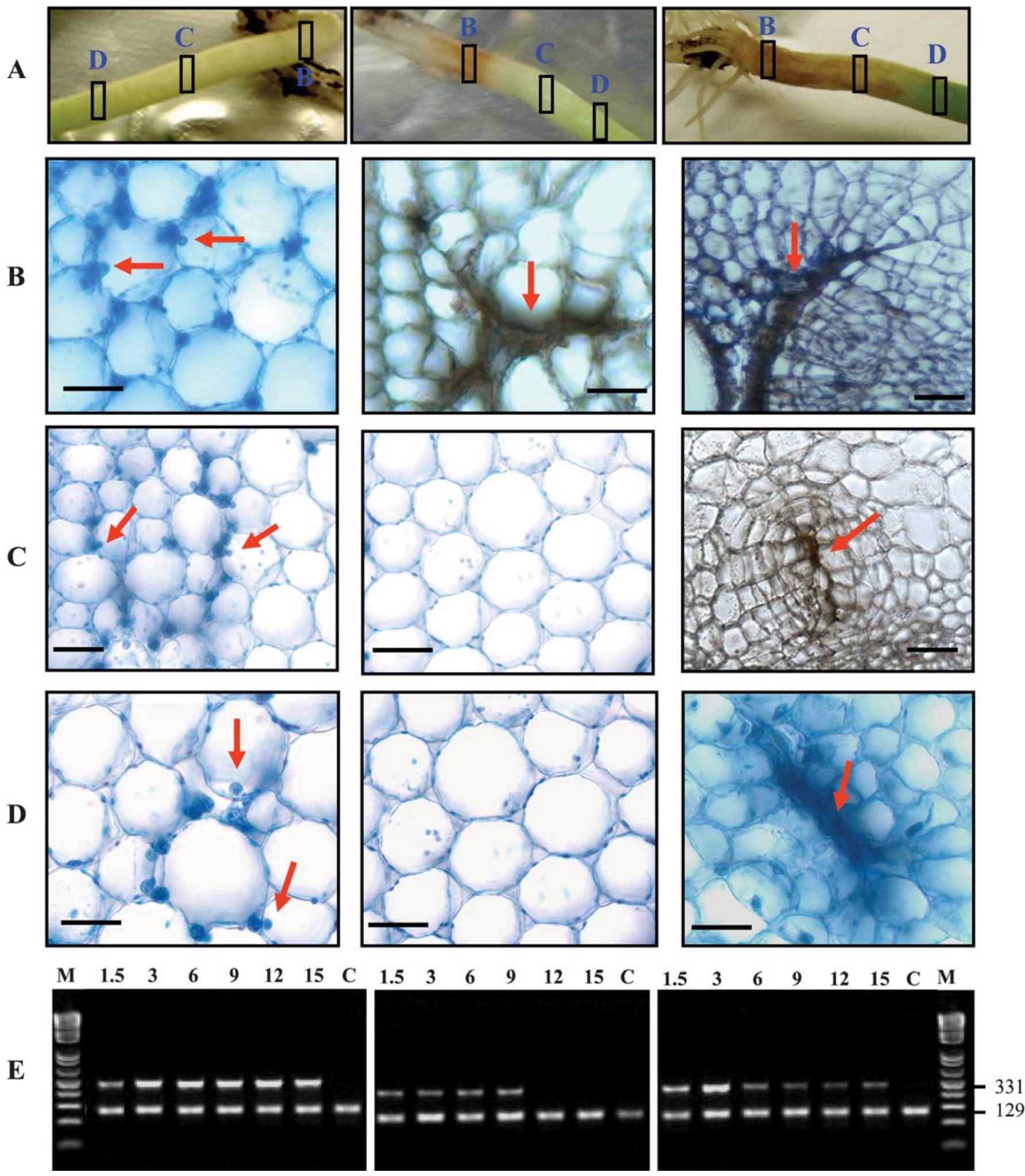

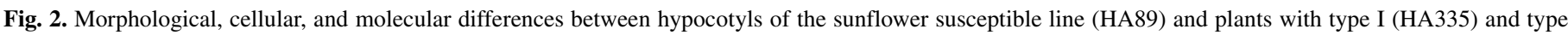

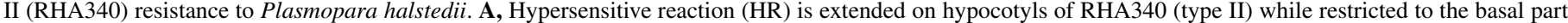

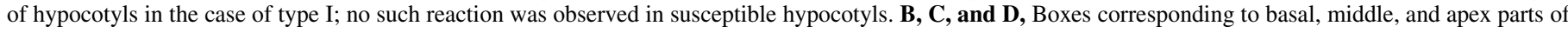

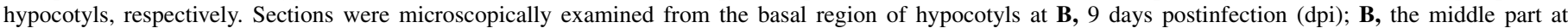

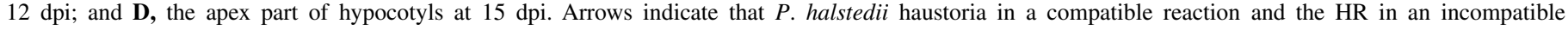

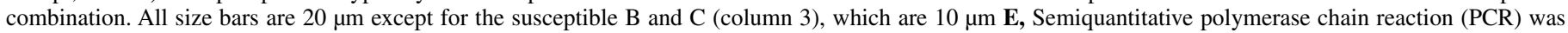

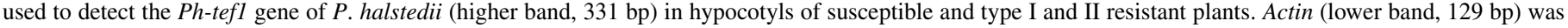

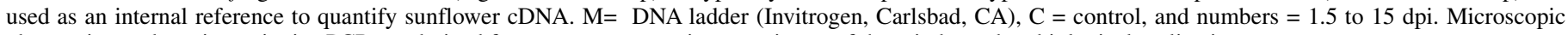
observation and semiquantitative PCR are derived from one representative experiment of three independent biological replications. 
this region, including LRR1 (576 to 597), LRR2 (599 to 620), LRR3 (622 to 643), LRR4 (645 to 667), LRR5 (803 to 824), LRR6 (860 to 879), and LRR7 (881 to 903).

The amino acid sequence predicted from RGC151 was divided into three domains. The first is a TIR domain (amino acids 21 to 163). The second domain is an NBS (amino acids 205 to 489) region. The third domain is an LRR, and includes the $\mathrm{C}$ terminus (amino acids 490 to 1021). Several LRR motifs were detected in this region, including LRR1 (672 to 691), LRR2 (695 to 716), LRR3 (742 to 764), LRR4 (766 to 788), LRR5 (823 to 846), LRR6 (848 to 868), and LRR7 (871 to 896). RGC203 and RGC155 proteins were similar to sunflower RGCs and other $R$ genes encoding NBS-LRR proteins (Supplemental Table 2) and they were $28 \%$ similar between them. RGC203 was 35 and $28 \%$ similar to the HA-NTIR11 RGC from sunflower (accession number AATO8955) and the Rp1 protein from maize (accession number AAP81261), respectively. The RGC151 protein shares similarity of 22 and $35 \%$ with the HA-NTIR11 RGC from sunflower (accession number AATO8955) and the $\mathrm{N}$ protein from tobacco (accession number BAB11635), respectively. A phylogenetic comparison of the NBS domains of these two RGCs with those of other R proteins (Fig. 3) revealed that the RGC203 protein belongs to a clade that contains the Ha-NTIR11 and HaNTIR3 RGCs (accession numbers AATO8955 and AATO8953) from sunflower, the Pot protein from black cottonwood (accession number XP_002335004), and R proteins Rp1 from maize (accession number AAP81262), Xa1 from rice (accession number BAA25068), and I2 from tomato (accession number AAD27815).

The RGC151 protein belongs to a different clade that contains the PU3 RGC from sunflower (accession number AALO7535); the RPS4, RPP5, and RPP1 proteins from Arabidopsis thaliana (accession numbers CAB53785, AAF08790, and AAC72977); and the $\mathrm{N}$ protein from tobacco (accession number Q40392).

Expression analysis of sunflower RGCs. Real-time PCR was used to detect the relative gene expression of sunflower RGCs following infection by $P$. halstedii. Total RNA was isolated from infected and uninfected hypocotyls of susceptible and resistant plants. The relative expression level of each RGC in hypocotyls of different sunflower lines is shown in Figure 4. In general, all RGC transcripts are constitutively expressed in mock-infected tissues; however, the transcripts of RGC203 (Fig. 4A) and HA-NTIR11 (Fig. 4B) were specifically enhanced in infected hypocotyls of lines 290004 and RHA340, respectively (type II resistance). This induction increased dramatically until $9 \mathrm{dpi}$, and then decreased to control levels at 12 dpi (Fig. 4A and B). No enhancement of RGC203 and HA-NTIR11 transcripts was detected in hypocotyls of other lines (Fig. 4A and B). On the other hand, no significant enhancement of RGC151 (Fig. 4C) and PU3 transcripts (Fig. 4D) was detected in infected or uninfected hypocotyls of all lines that were used in this study.

Resistance occurs over a longer portion of the hypocotyls in type II than in type I. Real-time PCR was used to detect the transcript accumulation of some defense and signaling-component genes. Induction of PR genes under biotic stress is a strong indicator that the plant resistance mechanisms have been triggered against an invading pathogen. In incompatible interactions, the PR5 transcript was induced at $3 \mathrm{dpi}$, reached its maximum accumulation at $6 \mathrm{dpi}$, and then decreased (Fig. 5). However, the transcript accumulation of $P R 5$ in type II resistance was five to six times higher than in type I resistance. On the other hand, a late (15 dpi) and weak transcript accumulation of PR5 was observed in the compatible interaction. The hsr203J sunflower homologue was induced at $1.5 \mathrm{dpi}$ for both types of resistance. The transcript from this gene reached its maximum accumulation at 3 dpi in the case of type I resistance and then decreased by 6 dpi. In contrast, in type II resistance, it reached its maximum accumulation at 6 dpi and then decreased by 9 dpi. However, the level of transcript accumulation in the case of type II resistance was six to nine times higher than in type I resistance. No such induction of $h s r 203 \mathrm{~J}$ transcript was detected in the case of a compatible interaction (Fig. 5), indicating an absence of HR.

\section{DISCUSSION}

In sunflower, two types of resistance to $P$. halstedii have been reported $(14,27,43)$. In type I resistance, growth of the pathogen is limited to the roots and the lower part of the hypocotyls whereas, in type II resistance, the pathogen grows through the whole length of the hypocotyls and may sporulate on the cotyledons. In this study, five lines were selected that differentially react to P 300 of $P$. halstedii. HA89 is a susceptible line that was extensively used as a recurrent parent and susceptible line in many studies of downy mildew on sunflower (10,26,37). HA335 and RHA419 are examples of lines that have type I resistance and RHA340 and 29004 are examples of lines that have type II resistance. P 300 sporulates heavily on cotyledons and true leaves of HA89, whereas no sporulation on true leaves was detected on resistant plants. Although RHA340 and 29004 lines permitted slight sporulation on cotyledons, with initiation of HR, no sporulation or HR was detected on cotyledons of the HA335 and HA419 lines. The observed symptoms on plants with type II resistance were characteristic of the so-called CLI $(14,43)$, where the pathogen does not reach the true leaves $(27,28)$. The compatible interaction between susceptible sunflower and $P$. halstedii was described in detail by previous researchers, who reported that the pathogen colonization became systemic after the primary infection started in the roots and then moved up to the hypocotyls $(12,27,28,39)$. Phenotypic observations and the semiquantitative PCR data in the present study suggest that pathogen growth differs according to hostpathogen combinations, and that these differences can be successfully measured using semiquantitative PCR. The phenotype of type II resistance is characterized by a range of reactions that depend on which host genotypes and pathogen pathotypes are involved. The phenotype ranges from pathotypes that cause necrosis on the cotyledons, such as the P 300 that was used in this study, to pathotypes that produce little sporulation and hardly any necrosis $(26,36,48)$. It is interesting to note that type II resistance

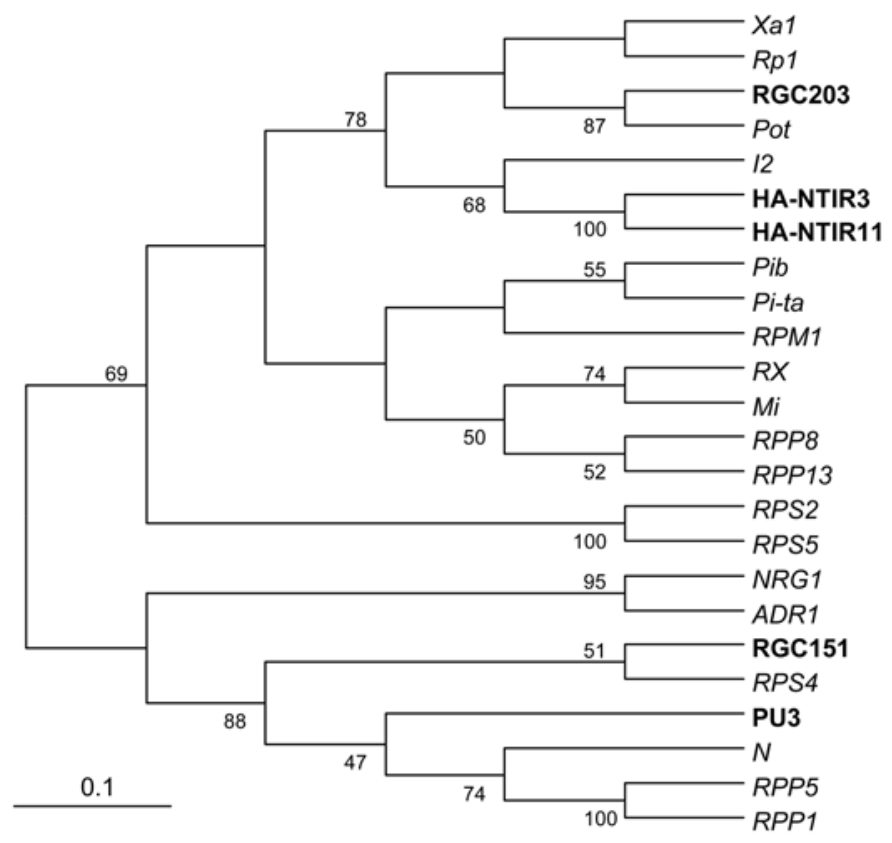

Fig. 3. Phylogenetic comparison of RGC203 and RGC151 with sunflower resistance gene candidates (RGCs) and other plant resistance genes. Numbers shown on branches are percentages of bootstrap replications supporting nodes. Phylogenetic analysis was conducted using MEGA 3.1. 

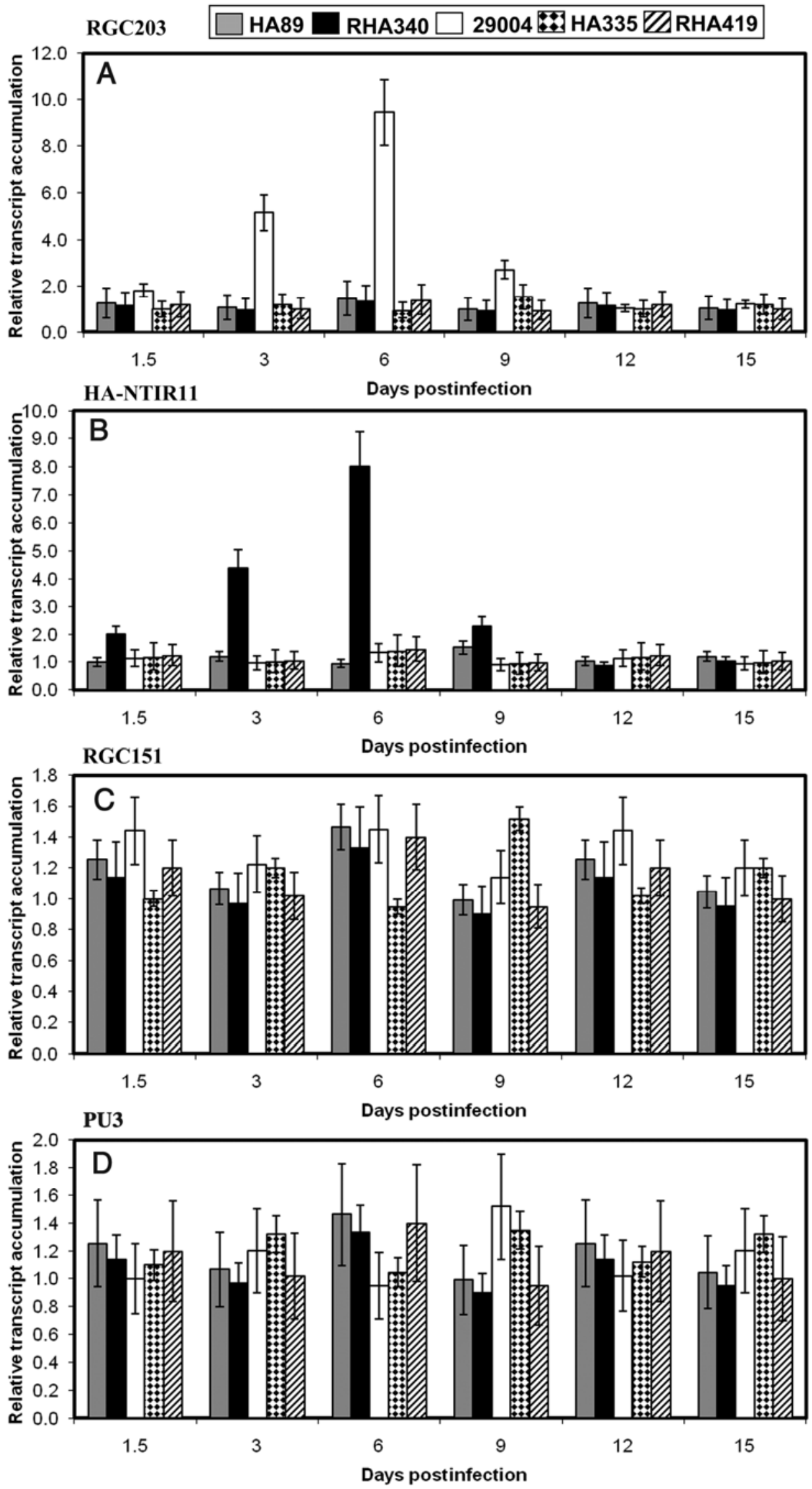

Fig. 4. Transcript accumulations of A, RGC203; B, HA-NTIR11; C, RGC151; and D, PU3 in hypocotyls of sunflower lines HA89 (susceptible), RHA340 (resistant type II), 29004 ( resistant type II), HA335 (resistant type I), and RHA419 (resistant type I) following infection by P 300 of Plasmopara halstedii. In each histogram, the means of three biological replicates were represented \pm standard deviation $(n=3)$. Bars from left to right: gray bars, HA89; black bars, RHA340; white bars, 29004; black spotted bars, RH335; and striped bars, RHA419. Relative gene expression is considered up if it is $\geq 1.5$-fold change, whereas it is considered down if it is $\leq-1.5$ fold change. 
is effective against a large number of pathotypes. For example, the RHA340 line, which develops sporulation on cotyledons, is resistant to all known pathotypes (36). It seems that type II resistance takes some time to be effective in the plant but is quite sufficient in the field (48).

One of the main objectives of this study was to investigate the possible relations between the two types of resistance and differences in the sequence types and transcript accumulation in plants with the two types of resistance upon infection. In this study, the transcript accumulation of four sunflower RGCs was detected using real-time PCR. PU3 and HA-NTIR11 were previously described $(6,35)$, while RGC203 and RGC151 were previously mapped to different locations of LG1 of sunflower (37), and were associated with the corresponding $\mathrm{Pl}_{14}$ (4) and $P l_{\text {Arg }}(8,49)$ downy mildew $R$ genes, respectively. Amino acid sequence analysis of RGC203 and RGC151 revealed that these proteins belong to the CC-NBS-LRR and TIR-NBS-LRR classes of plant $R$ genes, respectively, and have a high degree of similarity to other plant $\mathrm{R}$ proteins. The enhancement of transcription of RGC203 and HA-NTIR11 in infected hypocotyls of the 29004 and RHA340 lines may be characteristic of these lines to P 300. In contrast, no such induction of RGC151 and PU3 was detected in infected hypocotyls of lines that were used in this study. Plant disease $R$ gene products appear to interact directly or indirectly with products of pathogen $A v r$ genes $(17,18,32)$. Although the pathogen genes provide the ligands, $\mathrm{R}$ proteins employed as receptors and their genes are usually constitutively expressed at low levels to guarantee the presence of these receptors in the absence of pathogens, in order to rapidly detect the pathogen $(18,32)$. However, the expression of some disease $R$ genes was either induced or significantly enhanced upon pathogen infection $(13,15,22,38,41,51)$. Both Ha-NTR11 and 203 RGCs (this study; 38) are constitutively expressed in mock-infected plants, with dramatically enhanced expression after $P$. halstedii infection, suggesting that the amount of the $R$-gene product may be important for type II resistance mediated by such genes. In type II-resistant plants, the pathogen grows through the entire hypocotyl, such that substantially more tissue is subjected to the infection and HR compared with type I resistance. Transcript expression of HANTIR11 and RGC203 during the defense response probably leads
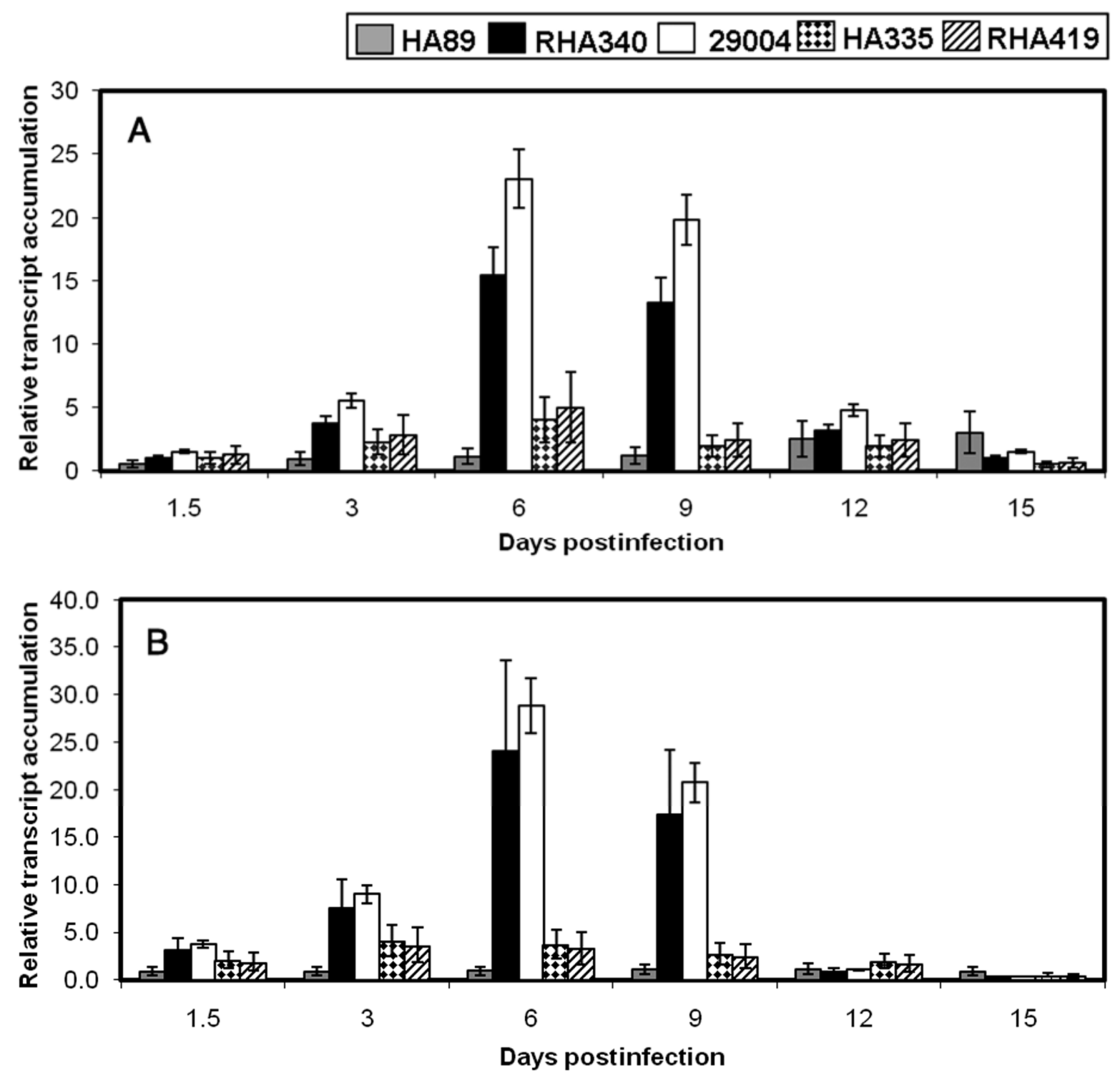

Fig. 5. Transcript accumulations of defense-related genes A, $P R 5$ and $\mathbf{B}$, hsr203J in hypocotyls of sunflower lines HA89 (susceptible), RHA340 (type II), 29004 (type II), HA335 (type I), and RHA419 (type I) infected by the oomycete Plasmopara halstedii. PR5 = pathogenesis-related protein. In each histogram, the means of three biological replicates were represented \pm standard deviation $(n=3)$. Bars from left to right: gray bars, HA89; black bars, RHA340; white bars, 29004; black spotted bars, RH335; and striped bars, RHA419. Relative gene expression is considered up if it is $\geq 1.5$-fold change, whereas it is considered down if it is $\leq-1.5$ fold change. 
to an HR similar to that with the RPW8.1 and $R P W 8.2$ genes, where their enhanced transcription via salicylic acid feedback is necessary to induce the HR in Arabidopsis infected by Erysiphe cichoracearum (50). The induction of an HR in the upper part of plant hypocotyls (resistant type II) was demonstrated by microscopic examination and by $h s r 203 j$ as a marker of HR induction. The $h s r 203 J$ gene from tobacco is specifically activated during an HR (34). Activation is rapid and occurs in various incompatible combinations involving tobacco and sunflower $(34,38,39)$. In addition, the current results point to initiation of the HR in cotyledons of plants with type II resistance after the tissue has been invaded by $P$. halstedii (Fig. 1C). The HR observed on cotyledons of type II-resistant plants is microscopically visible (Fig. 1B and C); therefore, it seems that it is different from the micro-HRs that are difficult to observe microscopically and which are initiated as a systemic response (3).

In conclusion, in type I resistance, it seems that the constitutive expression of PU3 and RGC151 is enough to guarantee recognition (either directly or indirectly) of the products of pathogen $A v r$ genes and to induce the HR, which is localized only in the basal part of the hypocotyls. In this case, the HR is strong enough to restrict the spread of the pathogen toward the upper part of the hypocotyls. On the other hand, in type II resistance, both an HR initiated as a consequence of direct or indirect recognition between the pathogen avr protein and host $\mathrm{R}$ protein (17), and systemic acquired resistance initiated by a signal transmitted from the infected area of the hypocotyls (39), are employed together to halt pathogen growth. Thus, the current results might validate our hypothesis about employment of two different resistance mechanisms by sunflower.

The cellular and molecular differences between the two types of sunflower resistance raise an interesting question about the molecular recognition between either type I or type II R and Avr proteins of $\mathrm{P} 300$. Most plant $R$ genes that have been isolated to date encode proteins which have NBS and LRR domains. The NBS region is preceded by either a CC domain or a so-called TIR domain (25). The signaling pathways mediated by NBS-LRR $R$ genes vary depending on which class of NBS-LRR is conditioning the resistance. For example, two different $R$-gene-mediated signaling pathways have been described in Arabidopsis-Hyaloperonospora parasitica interactions, depending on the type of $R$ gene. The first involves the TIR-NBS-LRR class (e.g., $R P P l$ and $R P P 5)$, and requires enhanced disease susceptibility (EDS1) and phytoalexin-deficient (PAD4) functions to provide full resistance. The second pathway involves the CC-NBS-LRR class (e.g., $R P P 7, R P P 8$, and $R P P 13$ ) and is independent of the function of $E D S 1, P A D 4, N D R 1$, and $P B S 2(1,5,23,33)$. In sunflower, sequences from the $P l_{6}$ and $P l_{A r g}$ genes belong to the TIR-NBS-LRR class (6; this work), whereas those from the $\mathrm{Pl}_{8}$ and $\mathrm{Pl}_{14}$ genes belong to the CC-NBS-LRR class (35; this work). Both the Pl6 and $\mathrm{Pl}_{\mathrm{Arg}}$ (TIR-NBS-LRR) and $\mathrm{Pl}_{8}$ and $\mathrm{Pl}_{14}$ (CC-NBS-LRR) clusters harbor $R$ genes to sunflower downy mildew isolate $\mathrm{P} 300$, the four sequences of sunflower that were mapped in different genomic locations and may confer resistance to isolate P 300 of the downy mildew pathogen. The complexity and independence of the four clusters facilitate selection for resistance to multiple pathotypes and the development of inbred lines and hybrids resistant to multiple pathotypes (37). Because the HA335 and RHA419 lines carry sequences belonging to the TIR-NBS-LRR class of R proteins (6; this study) and the RHA340 and 29004 lines carry sequences belonging to the CC-NBS-LRR class (35; this study), genetic analysis is needed to confirm whether there is a correlation between the sequence types and sunflower resistance types. Because the $\mathrm{N}$ termini of sequences related to the $P l_{6}$ and $\mathrm{Pl}_{\text {Arg }}$ genes on one hand and to the $\mathrm{Pl}_{8}$ and $\mathrm{Pl}_{14}$ genes on another hand are different, it is possible that one or more effector proteins from $\mathrm{P} 300$ of $P$. halstedii are recognized by two different $\mathrm{R}$ proteins of sunflower. These may have different mechanisms (e.g., different guard proteins) (17), depending on the $\mathrm{N}$ terminus of the gene. It will be interesting to validate this attractive hypothesis by cloning genes conferring resistance to $\mathrm{P} 300$, and then conducting biochemical experiments using techniques such as immunoprecipitation.

\section{ACKNOWLEDGMENTS}

We thank T. Gulya (USDA-ARS, Fargo, ND) for his kind gift of $P$. halstedii Pathotype 300, D. Walker (USDA-ARS, Urbana, IL) for his critical reading of this manuscript, and Advanta Semillas Company (Balcarce, Argentina) for providing seed of line 29004

\section{LITERATURE CITED}

1. Aarts, N., Metz, M., Holub, E., Staskawicz, B. J., Daniels, M. J., and Parker, J. E. 1998. Different requirements for EDS1 and NDR1 by disease resistance genes define at least two $R$ gene-mediated signaling pathways in Arabidopsis. Proc. Natl. Acad. Sci. USA 95:10306-10311.

2. Altschul, S. F., Madden, T. L., Schaffer, A. A., Zhang, Z., Miller, W., and Lipman, D. J. 1997. Gapped BLAST and PSI-BLAST: A new generation of protein database search programs. Nucleic Acids Res. 25:3389-3402.

3. Alvarez, M. E., Pennell, R. I., Meijer, P. J., Ishikawa, A., Dixon, R. A., and Lamb, C. 1998. Reactive oxygen intermediates mediate a systemic signal network in the establishment of plant immunity. Cell 92:773-784.

4. Bachlava, E., Radwan, O., Abratti, G., Tang, S., Gao, W., Heesacker, A. F., Bazzalo, M. E., Zambelli, A., Leon, A. J., and Knapp, S. J. 2011. Downy mildew $\left(\mathrm{Pl}_{8}\right.$ and $\left.\mathrm{Pl}_{14}\right)$ and rust $\left(R_{A d v}\right)$ resistance genes reside in close proximity to tandemly duplicated clusters of non-TIR-like NBSLRR-encoding genes on sunflower chromosomes 1 and 13. Theor. Appl. Genet. doi 10.1007/s00122-010-1525-0.

5. Bittner-Eddy, P. D., and Beynon, J. L. 2001. The Arabidopsis downy mildew resistance gene, $R P P 13-N d$, functions independently of NDR1 and EDS1 and does not require the accumulation of salicylic acid. Mol. Plant-Microbe Interact. 14:416-421.

6. Bouzidi, M. F., Badaoui, S., Cambon, F., Vear, F., Tourvielle De Labrouhe, D. Nicolas, P., and Mouzeyar, S. 2002. Molecular analysis of a major locus for resistance to downy mildew in sunflower with specific PCR-based markers. Theor. Appl. Genet. 104:592-600.

7. de Pinto, M. C., Tommasi, F., and De Gara, L. 2002. Changes in the antioxidant systems as part of the signaling pathway responsible for the programmed cell death activated by nitric oxide and reactive oxygen species in tobacco Bright-Yellow 2 cells. Plant Physiol. 130:698-708.

8. Dußle, C. M., Hahn, V., Knapp, S. J., and Bauer, E. 2004. $P l_{A r g}$ from Helianthus argophyllus is unlinked to other known downy mildew resistance genes in sunflower. Theor. Appl. Genet. 109:1083-1086.

9. Flor, H. H. 1971. Current status of the gene-for-gene concept. Annu. Rev. Phytopathol. 9:275-296.

10. Gedil, M. A., Slabaugh, M. B., Berry, S., Johnson, R., Michelmore, R., Miller, J., Gulya, T., and Knapp, S. J. 2001. Candidate disease resistance genes in sunflower cloned using conserved nucleotide-binding site motifs: Genetic mapping and linkage to the downy mildew resistance gene $P l 1$. Genome 44:205-212.

11. Göre, M. E. 2008. Epidemic outbreaks of downy mildew caused by Plasmopara halstedii on sunflower in Thrace, part of the Marmara region of Turkey. New Dis. Rep. 18.

12. Gray, A. B., and Sackston, W. E. 1985. Early stages of infection of resistant and susceptible sunflower seedlings by three races of Plasmopara halstedii. Can. J. Bot. 63:1725-1729.

13. Gu, K. Y., Yang, B., Tian, D. S., Wu, L. F., Wang, D. J., Sreekala, C., Yang, F., Chu, Z. Q., Wang, G. L., White, F. F., and Yin, Z. C. 2005. $R$ gene expression induced by a type-III effector triggers disease resistance in rice. Nature 435:1122-1125.

14. Gulya, T. J., Sackston, W. E., Viranyi, F., Masirevic, S., and Rashid, K.Y. 1991. New races of the sunflower downy mildew pathogen (Plasmopara halstedii) in Europe and North and South America. J. Phytopathol. 132:303-311.

15. Halterman, D. A., Wei, F. S., and Wise, R. P. 2003. Powdery mildew induced Mla mRNAs are alternatively spliced and contain multiple upstream open reading frames. Plant Physiol. 131:558-567.

16. Hammond-Kosack, K. E., and Jones, J. D. G. 1996. Resistance genedependent plant defense responses. Plant Cell 8:1773-1791.

17. Hammond-Kosack, K. E., and Parker, J E. 2003. Deciphering plantpathogen communication: Fresh perspectives for molecular resistance breeding. Curr. Opin. Biotechnol. 14:177-193.

18. Jones, J. D., and Dangl, J. L. 2006. The plant immune system. Nature 16:323-329.

19. Kovtun, Y., Chiu, W. L., Tena, G., and Sheen, J. 2000. Functional analysis 
of oxidative stress activated mitogen-activated protein kinase cascade in plants. Proc. Natl. Acad. Sci. USA 97:2940-2945.

20. Levine, A., Pennell, R. I., Alvarez, M. E., Palmer, R., and Chris Lamb, C. 1996. Calcium-mediated apoptosis in a plant hypersensitive disease resistance response. Curr. Biol. 6:427-437.

21. Levine, A., Tenhaken, T. R., Dixon, R., and Lamb, C. $1994 . \mathrm{H}_{2} \mathrm{O}_{2}$ from the oxidative burst orchestrates the plant hypersensitive disease resistance response. Cell 79:583-593.

22. Levy, M., Edelbaum, O., and Sela, I. 2004. Tobacco mosaic virus regulates the expression of its own resistance gene $N$. Plant Physiol. 135:2392-2397.

23. McDowell, J. M., Cuzick, A., Can, C., Beynon, J., Dangl, J. L., and Holub, E. B. 2000. Downy mildew (Peronospora parasitica) resistance genes in Arabidopsis vary in functional requirements for NDR1, EDS1, NPRI and salicylic acid accumulation. Plant J. 22:523-529.

24. McMaugh, S. J., and Lyon, B.R. 2003. Real-time quantitative RT-PCR assay of gene expression in plant roots during fungal pathogenesis. Biotechniques 34:982-986.

25. Meyers, B. C., Dickerman, A. W., Michelmore, R. W., Pecherer, R. M., Sivaramakrishnan, S., Sobral, B., and Young, N. D. 1999. Plant disease resistance genes encode members of an ancient and diverse protein family within the nucleotide binding super family. Plant J. 20:317-332.

26. Miller, J. F., and Gulya, T. J. 1988. Registration of six downy mildew resistant sunflower germplasm lines. Crop Sci. 28:1040-1041.

27. Mouzeyar, S., Tourvieille de Labrouhe, D., and Vear, F. 1993. Histopathological studies of resistance of sunflower (Helianthus annuus L.) to downy mildew (Plasmopara halstedii). J. Phytopathol. 139:289-297.

28. Mouzeyar, S., Tourvieille de Labrouhe, D., and Vear, F. 1994. Effect of host-race combination on resistance of sunflower, Helianthus annuus L., to downy mildew Plasmopara halstedii. J. Phytopathol. 141:249-258.

29. Mulpuri, S., Liu, Z., Feng, J., Gulya, T. J., and Jan, C.-C. 2009. Inheritance and molecular mapping of a downy mildew resistance gene, Pl13 in cultivated sunflower (Helianthus annuus L.). Theor. Appl. Genet. 119:795-803.

30. Neill, S, Desikan, R., and Hancock, J. 2002. Hydrogen peroxide signaling. Curr. Opin. Plant Biol. 5:388-395.

31. Nicholas, K. B., Nicholas, H. B., and Deerfield, D. W. 1997. GeneDoc: Analysis and visualization of genetic variation. EMBnet News 4:14.

32. Panstruga, R., Parker, J. E., and Schulze-Lefert, P. 2009. SnapShot: Plant immune response pathways. Cell 136:978.

33. Peart, J. R., Cook, G., Feys, B. J., Parker, J. E., and Baulcombe, D. C. 2002. An EDS1 orthologue is required for N-mediated resistance against tobacco mosaic virus. Plant J. 29:569-579.

34. Pontier, D., Godiard, L., Marco, Y., and Roby, D. 1994. HSR203J, a tobacco gene whose activation is rapid, highly localized and specific for incompatible plant/pathogen interactions. Plant J. 5:507-521.

35. Radwan, O., Bouzidi, M. F., Nicolas, P., and Mouzeyar, S. 2004. Development of PCR markers for the Pl5/Pl8 locus for resistance to Plasmopara halstedii in sunflower, Helianthus annuus L. from complete CC-NBS-LRR sequences. Theor. Appl. Genet. 109:176-185.

36. Radwan, O., Bouzidi, M. F., Vear, F., Philippon, J., Tourvieille de Labrouhe, D., Nicolas, P., and Mouzeyar, S. 2003. Identification of nonTIR-NBS-LRR markers linked to Pl5/Pl8 locus for resistance to downy mildew in sunflower. Theor. Appl. Genet. 106:1438-1446.

37. Radwan, O., Gandhi, S., Heesacker, A., Whitaker, B., Taylor, C., Plocik, A., Kesseli, R., Kozik, A., Michelmore, R. W., and Knapp, S. J. 2008.
Genetic diversity and genomic distribution of homologs encoding NBSLRR disease resistance proteins in sunflower. Mol. Genet. Genomics 280:111-125.

38. Radwan, O., Mouzeyar, S., Nicolas, P., and Bouzidi, M. F. 2005. Induction of a sunflower CC-NBS-LRR resistance gene analogue during incompatible interaction with Plasmopara halstedii. J. Exp. Bot. 412:567575.

39. Radwan, O., Mouzeyar, S., Venisse, J. S., Nicolas, P., and Bouzidi, M. F. 2005. Resistance of sunflower to biotrophic oomycete Plasmopara halstedii is associated with a delayed hypersensitive response within the hypocotyls. J. Exp. Bot.420:2683-2693.

40. Rashid, K. Y. 1993. Incidence and virulence of Plasmopara halstedii on sunflower in Western Canada during 1988-1991. Can. J. Plant Pathol. 15:206-210.

41. Romer, P., Hahn, S., Jordan, T., Strauss, T., Bonas, U., and Lahaye, T. 2007. Plant pathogen recognition mediated by promoter activation of the pepper Bs3 resistance gene. Science 318:645-648.

42. Rozen, S., Skaletsky, H. J., Krawetz, S., and Misener, S. 2000. Bioinformatics methods and protocols. Page 365-386 in: Methods in Molecular Biology. S. Krawetz and S. Misener, eds. Humana Press, Totowa, NJ.

43. Sackston, W E. 1992. Cotyledon limited infection (CLI) and leaf disk immersion (LDI) inoculation of sunflower by downy mildew (Plasmopara halstedii). Pages 840-848 in: Proc. 13th Sunflower Int. Conf., National Sunfower Association, Mandan, ND.

44. Tang, S., Hass, C. G., and Knapp, S. J. 2006. Ty3/gypsy-like retrotransposon knockout of a 2-methyl-6-phytyl-1,4-benzoquinone methyltransferase is non-lethal, uncovers a cryptic paralogous mutation, and produces novel tocopherol (vitamin E) profiles in sunflower. Theor. Appl. Genet. 113:783-799.

45. Thompson, J. D., Gibson, T. J., Plewniak, F., Jeanmougin, F., and Higgens, D. G. 1997. The CLUSTAL-X windows interface: Flexible strategies for multiple sequence alignment aided by quality analysis tools. Nucleic Acids Res. 25:4876-4882.

46. Tosi, L., and Beccari, G. 2007. A new race, 704, of Plasmopara halstedii pathogen of sunflower downy mildew in Italy. Plant Dis. 91:463.

47. Unger, S., Büche, C., Boso, S., and Kassemeyer, H. H. 2007. The course of colonization of two different Vitis genotypes by Plasmopara viticola indicates compatible and incompatible host-pathogen interactions. Phytopathology 97:780-786.

48. Vear, F., Tourvieille de Labrouhe, D., and Miller, J. F. 2003. Inheritance of the wide-range downy mildew resistance in the sunflower line RHA 419. Hella 26:19-24.

49. Wieckhorst, S., Dußle, C. M., Bachlava, E., Radwan, O., Tang, S., Knapp, S. J., Schön, C. C., Hahn, V., and Bauer, E. 2009. Identifying candidate genes for the $P l_{\text {Arg }}$ resistance locus against Plasmopara halstedii introduced into cultivated sunflower (Helianthus annuus) from the wild species $H$. argophyllus. In: 8th Plant Genomics Eur. Meet. Lisbon, Portugal. National Plant Genomics Programmers, Europe.

50. Xiao, S., Brown, S., Patrick, E., Brearley, C., and Turner, J. G. 2003. Enhanced transcription of the Arabidopsis disease resistance genes $R P W 8.1$ and $R P W 8.2$ via a salicylic acid-dependent amplification circuit is required for hypersensitive cell death. Plant Cell15:33-45.

51. Yoshimura, S., Yamanouchi, U., Katayous, Y., Toki, S., Wang, Z. X., Kono, I., Kurata, N., Yano, M., Iwata, N., and Sasaki, T. 1998. Expression of $\mathrm{Xa1}$, a bacterial blight-resistance gene in rice, is induced by bacterial inoculation. Proc. Natl. Acad. Sci. USA 95:1663-1668. 